\title{
COMPARATIVE ANALYSIS OF ANTIOXIDANT ACTIVITY AND PHYTOCHEMICAL CONTENTS IN ETHANOLIC LEAF EXTRACTS OF IN VITRO AND FIELD GROWN WITHANIA SOMNIFERA
}

\author{
PRABHJOT SINGH JASSAL ${ }^{1 *}$, GAGANDEEP KAUR ${ }^{2}$ \\ ${ }^{1}$ Department of Biotechnology and Biosciences, Lovely Professional University, Phagwara - 144 411, Punjab, India. \\ Email: prabh_jyot2006@yahoo.co.in
}

Received: 09 June 2016, Revised and Accepted: 20 June 2016

\section{ABSTRACT}

Objective: The present study was planned to compare antioxidant activity in vitro and field grown Withania somnifera was assessed using 1 , 1-diphenyl-2-picrylhydrazyl (DPPH) and nitric oxide (NO) assays. Medicinal plants are a major source of phytochemicals used for the treatments of human diseases. W. somnifera has anti-inflammatory, antioxidant, and antimicrobial properties.

Methods: Antioxidant activity and phytochemical contents in W. somnifera were determined spectrophotometrically.

Results: The results of antioxidant activity of field grown ethanolic leaf extract of $W$. somnifera showed maximum inhibition of $72.08 \%$ and $77.85 \%$ in DPPH $(50 \mu \mathrm{g} / \mathrm{ml})$ and NO $(100 \mu \mathrm{g} / \mathrm{ml})$ scavenging assays, respectively. Field grown ethanolic leaf extract of $W$. somnifera showed maximum concentrations of phenolics, flavonoids, and carotenoids, as active phytochemicals, determined spectrophotometrically, which were found as $676.5 \mu \mathrm{g} / \mathrm{ml}, 557.5 \mu \mathrm{g} / \mathrm{ml}$, and $469 \mu \mathrm{g} / \mathrm{ml}$, respectively, as compared to in vitro plant extracts.

Conclusions: This study demonstrated that antioxidant activity and phytochemical contents of field grown ethanolic leaf extract of $W$. somnifera were found to be comparatively higher than in vitro plant extracts. Leaf extracts of $W$. somnifera are a potential source of antioxidants and could prevent many free radical-related diseases.

Keywords: Carotenoids content, 1-diphenyl-2-picrylhydrazyl scavenging assay, Flavonoids content, Nitric oxide radical scavenging assay, Phenolic content.

(C) 2016 The Authors. Published by Innovare Academic Sciences Pvt Ltd. This is an open access article under the CC BY license (http://creativecommons. org/licenses/by/4. 0/) DOI: http://dx.doi.org/10.22159/ajpcr.2016.v9i5.13370

\section{INTRODUCTION}

In recent years, much attention has been devoted to natural antioxidants and their association with health benefits [1]. Nature has been a source of medicinal agents for thousands of year, and an impressive number of modern drugs have been made from natural resources [2]. Plant produces various antioxidative compounds to counteract reactive oxygen species (ROS) to survive [3]. ROS, which includes free radicals such as superoxide anion radicals, hydroxyl radicals, and non-free-radical species such as hydrogen peroxide and singlet oxygen, is various forms of activated oxygen. These molecules are exacerbating factors in cellular injury and aging process [4]. In foods, ROS can cause lipid peroxidation, which leads to the deterioration of the food [5]. The oxidative deterioration of the lipid-containing food is responsible for the rancid odors and flavors during processing and storage, consequently decreasing the nutritional quality and safety of foods, due to the formation of secondary, in fact potentially toxic compounds. The addition of antioxidant is a method for increasing the shelf life of food products [6].

Medicinal plants consist of secondary metabolites such as alkaloids, glycosides, steroids, and flavonoids which are the important sources of drugs [7]. Plant phenolics are commonly found in both edible and nonedible plants and have been reported to have multiple biological effects including antioxidant activity. The antioxidant activity of phenolics is mainly due to their redox properties, which allow them to act as reducing agents, hydrogen donators, and singlet oxygen quenchers. In addition, they have a metal chelation potential [8].

The phenolic compounds are increasingly of interest in the food industry because they retard oxidative degradation of lipids and thereby improve the quality and nutritional value of food [9]. The importance of natural phenolic compounds from plant materials is also raising interest among scientists, food manufacturers, and consumers due to functional food with specific health effects [10].
Withania somnifera is an ayurvedic herb and belongs to the family of Solanaceae, which has been used for centuries in India to improve overall health, vitality, and longevity. It is an Indian medicinal plant and also known as Ashwagandha, Ginseng, and Winter cherry [11]. Ashwagandha may be capable of providing excellent defensive effects on the nervous system and used for the treatment of degenerative diseases such as Alzheimer's and Parkinson's diseases [12]. This plant has proven powerful antioxidant properties that destroy the free radicals that have been concerned in aging and numerous disease states. Even more remarkable evidence suggests that $W$. somnifera has anticancer properties [13]. The leaves of $W$. somnifera are reported to contain different phytochemical constituents such as 5 unidentified alkaloids, glycosides, 12 withanolides, chlorogenic acid, condensed tannins, many free amino acids, glucose, and flavonoids [14]. Withaferin A is a steroidal lactone, and it is the most significant withanolide isolated from the leaf and dried root extracts of $W$. somnifera [15].

Another important fact related to the cultivation of plant has high dormancy, as germination of this plant is very poor. The seed viability of $W$. somnifera is limited to 1 year [16]. The explants directly collected from the field can have higher percentage of contamination than explants taken from in vitro for cultivation purposes. The study is conducted to develop a method for the better cultivation of plant from various explants (axillary nodes, young leaves, and internodes of $W$. somnifera) in vitro condition. The technique of micropropagation is applied with the objective of enhancing the rate of multiplication of plant species under study and to increase the content of various phytochemicals and other bioactive compounds in in vitro raised cultures of $W$. somnifera.

In view of this, the present investigation will be an attempt for the comparative analysis of field grown and in vitro cultivated $W$. somnifera in context to its antioxidant activity by 1,1-diphenyl-2-picrylhydrazyl (DPPH) and nitric oxide (NO) radical scavenging methods and also 
to determine the concentration of their phytochemical contents in ethanolic leaf extract of $W$. somnifera.

\section{METHODS}

\section{Collection of plant materials}

Young leaves of $W$. somnifera were collected from Botanical Garden of Lovely Professional University, Punjab, and the leaves were taken for further analysis.

\section{Chemicals}

DPPH, curcumin, and gallic acid were obtained from MP Biomedicals. Sodium carbonate was obtained from HiMedia Laboratories Pvt. Ltd. India. Folin-Ciocalteu reagent was obtained from Merck, Mumbai, India. Sodium nitroprusside (SNP) and quercetin were obtained from Sisco Research Laboratories Pvt., Ltd., Mumbai, India. Griess reagent, sulfanilamide solution, naphthyl ethylenediamine dihydrochloride, potassium acetate, aluminum chloride, and methanol were obtained from Loba Chemie, Mumbai, India.

\section{In vitro propagation of plants from explants}

In vitro cultivation of $W$. somnifera plants were done according to the standard method given by Viji et al. [17].

\section{Soxhlet extraction}

\section{Ethanol extract}

The dried leaves were grinded in coarse powder using high capacity grinding machine. The powdered plant material ( $20 \mathrm{~g}$ ) was successively extracted in a Soxhlet extractor at elevated temperature using $200 \mathrm{ml}$ of ethanol, and the extract was filtered through filter paper and poured on Petri dishes to evaporate the solvents from the extract to get dry extracts. After drying, crude extracts were weighted and stored in stock vials and kept in refrigerator $\left(0-4^{\circ} \mathrm{C}\right)$ for further use [18].

\section{In vitro and in vivo antioxidant and free radical scavenging activity} DPPH radical scavenging assay

Free radical scavenging capacity of in vitro and field grown ethanolic leaf extracts of $W$. somnifera was determined using DPPH assay method. Freshly prepared DPPH solution was taken in test tubes, and extracts were added followed by serial dilutions $(5-50 \mu \mathrm{g} / \mathrm{ml})$ to every test tube so that the final volume was $5 \mathrm{ml}$. After 30 minutes, the absorbance was read at $517 \mathrm{~nm}$ using a spectrophotometer. Gallic acid was used as standard. Control sample was prepared, containing the same volume without any extract and standard, and the absorbance was read at $517 \mathrm{~nm}$ using a spectrophotometer [19].

\section{NO radical scavenging assay}

At physiological pH, NO generated from SNP aqueous solution interacts with oxygen to produce nitrite ions measured by Griess reagent [20] NO scavenging assay was carried using SNP and determined by the use of the Griess reagent [21]. $2 \mathrm{ml}$ of $10 \mathrm{mM}$ SNP in $0.5 \mathrm{ml}$ phosphate buffer saline $(\mathrm{pH} 7.4)$ was mixed with $0.5 \mathrm{ml}$ of extract/sub-fraction at various concentrations and the mixture was incubated at $25^{\circ} \mathrm{C}$ for 150 minutes. From the incubated mixture $0.5 \mathrm{ml}$ was taken out and added into $1.0 \mathrm{ml}$ sulfanilamide solution $(0.33 \%$ in $20 \%$ glacial acetic acid) and further incubated at room temperature for 5 minutes. Finally, $1 \mathrm{ml}$ naphthyl ethylenediamine dihydrochloride $(0.1 \% \mathrm{w} / \mathrm{v})$ was mixed and maintained at room temperature for 30 minutes. The absorbance was measured at $546 \mathrm{~nm}$. A typical blank/control solution contained the same solution mixture without plant extract or standard. Curcumin was used as standard. The absorbance of the blank/control solution was measured at $546 \mathrm{~nm}$. The percentage inhibition was calculated according to the following equation:

$\%$ inhibition $=\left[\left(1-\mathrm{A}_{1} / \mathrm{A}_{0}\right)\right] \times 100$

Whereas $\mathrm{A}_{1}=$ Absorbance of the extract or standard; $\mathrm{A}_{0}=$ Absorbance of the control.

\section{Phytochemical analysis}

\section{Quantification of total phenolic content}

Total phenolic contents in in vitro and field grown ethanolic leaf extract of $W$. somnifera were determined by the Folin-Ciocalteu reagent method, according to the standard procedure described by Demiray et al. [22].

\section{Quantification of total flavonoids content}

Total flavonoid content in in vitro and field grown ethanolic leaf extract of $W$. somnifera was determined by aluminum chloride colorimetric method, according to the standard method given by Jiao and Wang [23].

\section{Quantification of total carotenoids content}

Carotenoids contents in vitro and field grown ethanolic leaf extract of $W$. somnifera were estimated according to the method given by Mahadevan and Sridhar [24].

\section{Statistical analysis}

The statistical analysis was performed to calculate the IC50 values using Microsoft Excel. IC50 was calculated from linear equation relationship, i.e., $\mathrm{y}=\mathrm{mx}+\mathrm{c}$, Whereas $\mathrm{y}=\%$ of inhibition and $\mathrm{x}=$ Concentration of compound. For IC50 value, $\mathrm{y}=50$ and $\times$ value was obtained as inhibitory concentration (IC50: Half maximal inhibitory concentration).

\section{RESULTS}

In vitro propagated plants from explants of field grown $W$. somnifera Explants from field grown $W$. somnifera were selected after pruning and used for in vitro propagation under controlled conditions. Since numerous plants can be grown under in vitro conditions as the explants suitable for in vitro propagation can be obtained throughout the year, large number of plantlets were obtained, when culture tubes were kept in the growth room at $25 \pm 2^{\circ} \mathrm{C}$, with a photoperiod of $16 \mathrm{hrs}$ daylight and 8 hrs night breaks under the cool white fluorescent light after the incubation was observed.

\section{Antioxidant activity of in vitro and field grown $\boldsymbol{W}$. Somnifera DPPH radical scavenging assay}

The free radical scavenging activity of ethanolic extract of $W$. somnifera was studied by its ability to reduce the DPPH, a stable free radical and any molecule that can donate an electron or hydrogen to DPPH, can react with it and thereby bleach the DPPH absorption [19]. DPPH is a purple color dye having absorbance at $517 \mathrm{~nm}$ and after showing reaction with a hydrogen donor, its purple color fades or disappears due to its conversion to a colorless compound when neutralized, resulting in decrease in absorbance. The results of antioxidant activity for field grown ethanolic leaf extract of $W$. somnifera showed the maximum activity of $72.08 \%$ (Fig. 1a) as compared to in vitro (Fig. 1b) at concentration of $50 \mu \mathrm{g} / \mathrm{ml}$, whereas Gallic acid (Fig. 1c) exhibited $77.87 \%$ inhibition at the same concentration. In vitro extracts of $W$. somnifera were observed to have the least free radical scavenging activity as compared to field grown ethanolic leaf extracts.

\section{NO radical scavenging assay}

NO radical is playing an important role in various types of inflammatory process. The production of NO radical at sustained levels, result in direct tissue toxicity, whereas chronic expression of $\mathrm{NO}$ radical is associated with various inflammatory conditions including juvenile diabetes, multiple sclerosis, arthritis, and ulcerative colitis [25]. NO, generated from SNP, is an unstable species and reacting with oxygen molecule produce stable nitrate. W. somnifera extracts also moderately inhibit nitrite formation, by directly competing with oxygen to react with NO. The results of antioxidant activity for field grown ethanolic leaf extract of $W$. somnifera showed the maximum activity of $77.85 \%$ (Fig. $2 \mathrm{a}$ ) as compared to in vitro (Fig. 2b) at $100 \mu \mathrm{g} / \mathrm{ml}$, whereas curcumin (Fig. 2c) exhibited $85.15 \%$ inhibition at the same concentration. In vitro extracts of $W$. somnifera were observed to have the least free radical scavenging activity as compared to field grown ethanolic leaf extracts. 


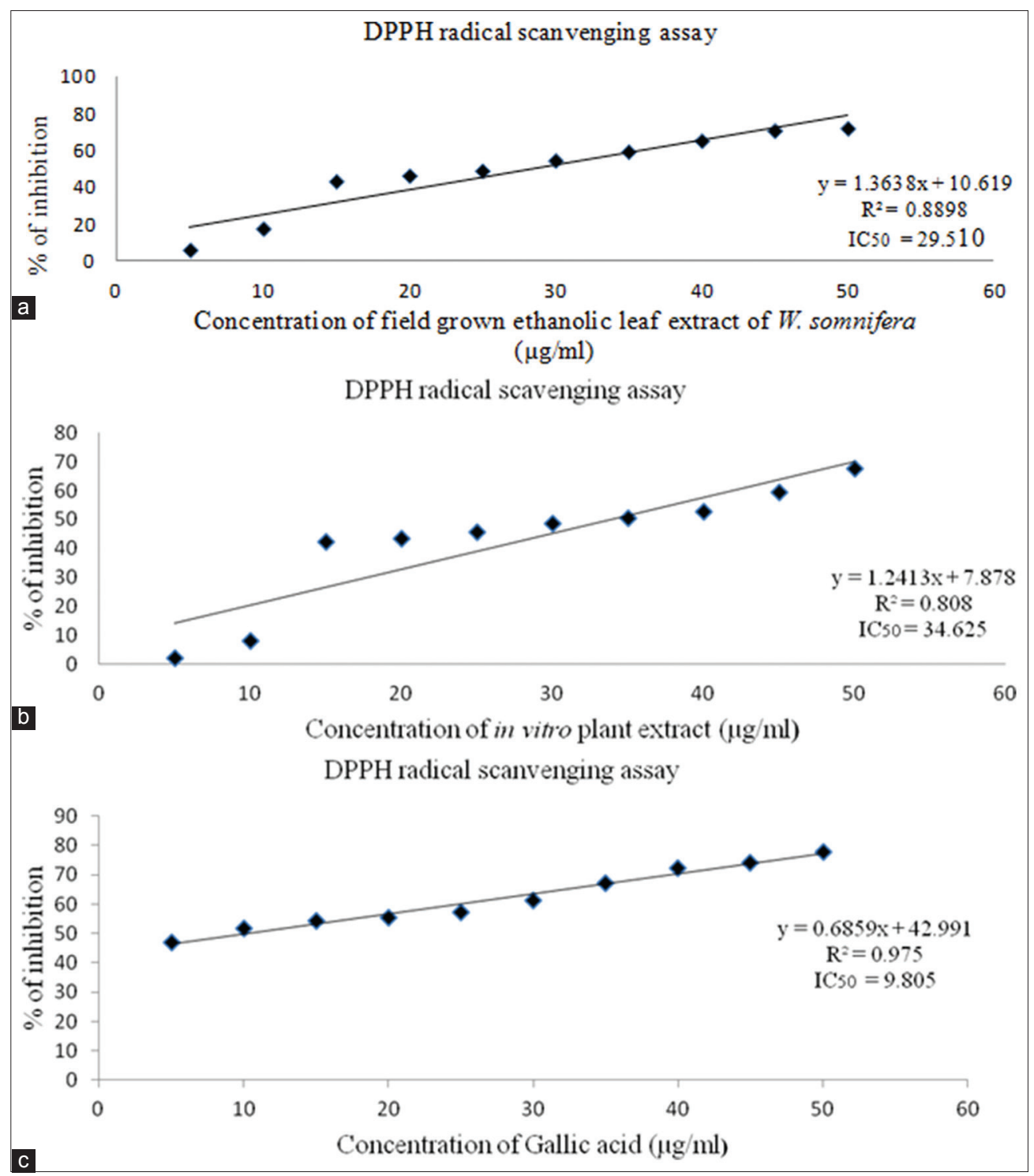

Fig. 1: 1, 1-diphenyl-2-picrylhydrazyl scavenging activity of (a) Field grown ethanolic leaf extract of Withania somnifera, (b) In vitro extracts of Withania somnifera, and (c) Gallic acid used as standard

\section{Phytochemical analysis}

Quantification of total phenolic content

Comparative analysis of total phenolic contents in in vitro and field grown ethanolic leaf extracts of $W$. somnifera was determined using the Folin-Ciocalteu reagent. The total phenolic contents of the test fractions were calculated using the standard curve of quercetin $(y=0.002 x+0.136)$ at different concentration of $100-1000 \mu \mathrm{g} / \mathrm{ml}$ at $720 \mathrm{~nm}$. The results of total phenolic content in field grown ethanolic leaf extract of $W$. somnifera were obtained as maximum at concentration of $676.5 \mu \mathrm{g} / \mathrm{ml}$ at $1.489 \mathrm{~nm}$ when compared to in vitro extract (Fig. 3). Literature reveals that antioxidant activity of plant extract is mainly due to the presence of phenolic compounds, which act as free radical scavengers and metal ion chelators.

\section{Quantification of total flavonoids content}

The comparative analysis of total flavonoids content in in vitro and field grown ethanolic leaf extract of $W$. somnifera was determined using the aluminum chloride colorimetric method. The concentration of total flavonoids content was calculated using the standard curve of quercetin $(y=0.002 x-0.243)$ at different concentration of $100-1000 \mu \mathrm{g} / \mathrm{ml}$ at $430 \mathrm{~nm}$. The results of total flavonoids content in field grown ethanolic leaf extract of $W$. somnifera were obtained as maximum at concentration of $557.5 \mu \mathrm{g} / \mathrm{ml}$ at $0.912 \mathrm{~nm}$ when compared to in vitro plant extract (Fig. 4).

\section{Quantification of total carotenoids content}

The total carotenoid contents in in vitro and field grown ethanolic leaf extract of $W$. somnifera were calculated using the standard curve of quercetin $(y=0.001 x+0.065)$ at different concentrations of $100-1000 \mu \mathrm{g} / \mathrm{ml}$ at $450 \mathrm{~nm}$. The maximum concentration of total carotenoids content in field grown ethanolic leaf extract was obtained as $469 \mu \mathrm{g} / \mathrm{ml}$ at $0.534 \mathrm{~nm}$ as compared to in vitro plant extract (Fig. 5).

\section{DISCUSSION}

Based on the results of this study, it can be discussed that field grown ethanolic leaf extract of $W$. somnifera showed maximum antioxidant activity of $72.08 \%$ than in vitro extract at $50 \mu \mathrm{g} / \mathrm{ml}$, in DPPH radical scavenging assay. In DPPH radical scavenging assay, chloroform, petroleum ether, and methanol extracts of $W$. somnifera showed maximum activity of $75.37 \%, 63.61 \%$, and $54.16 \%$, respectively, at $250 \mu \mathrm{g} / \mathrm{ml}$, as reported by Shahriar et al. [18]. Shah et al. reported that the antioxidant activity of extracts was increased, with increase 


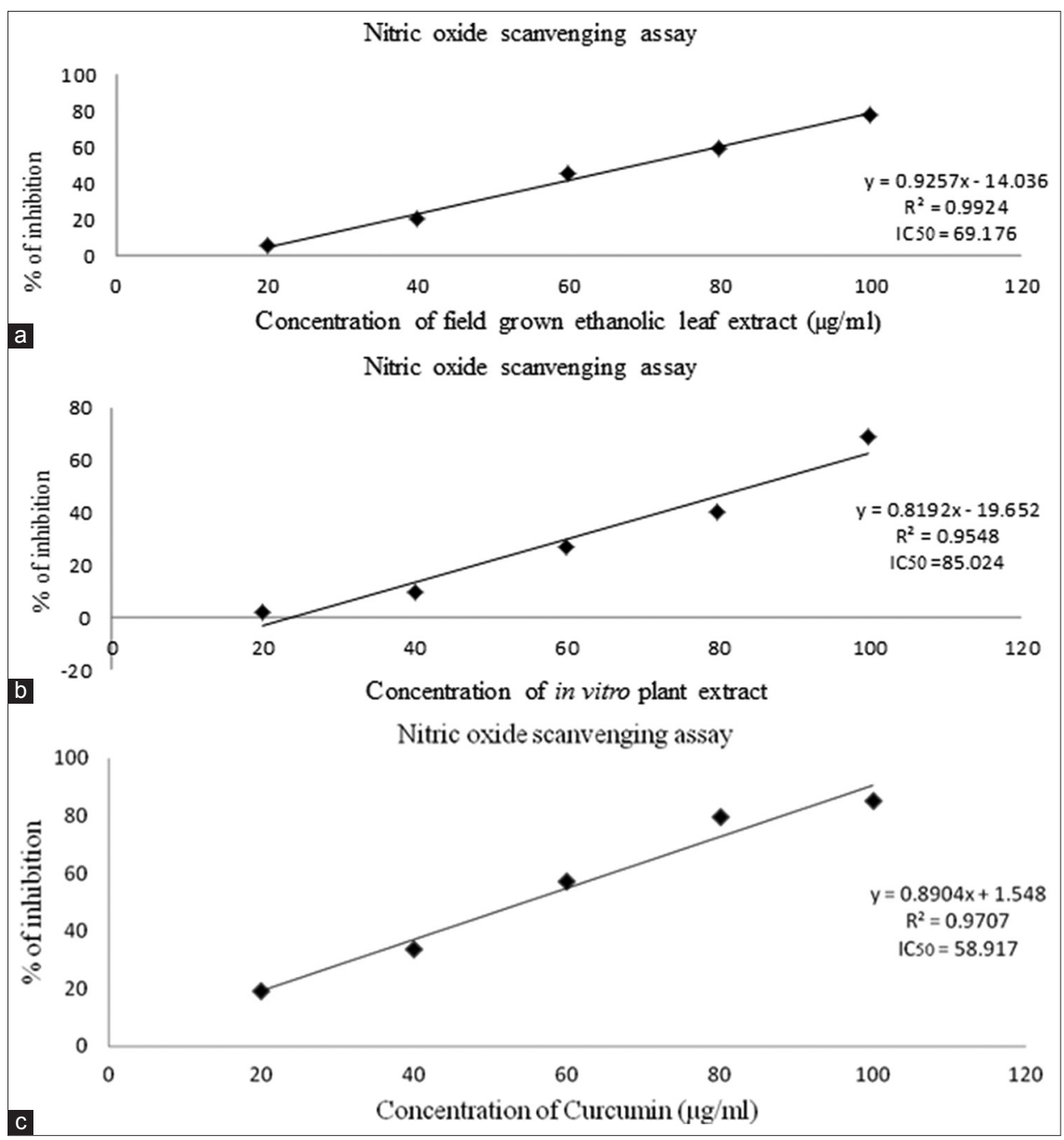

Fig. 2: Nitric oxide scavenging activity of (a) Field grown ethanolic leaf extract of W. somnifera, (b) In vitro extracts of W. somnifera, and (c) Curcumin used as standard

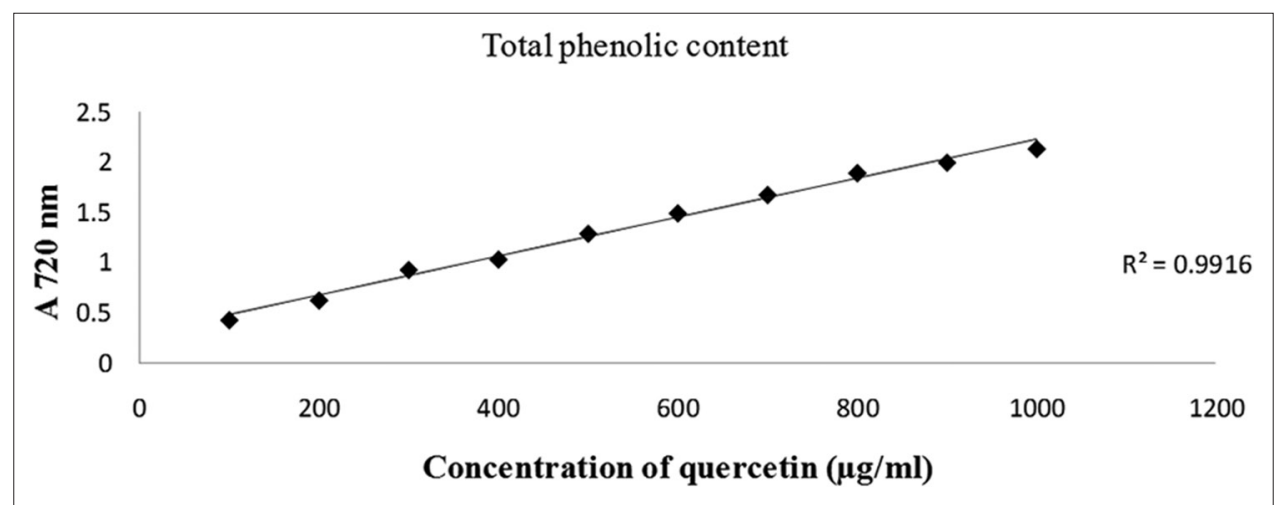

Fig. 3: Evaluation of total phenolic contents in in vitro and field grown ethanolic leaf extract of W. somnifera from standard curve of quercetin

in concentration of $W$. Somnifera [26]. According to the literature of Sharma and Sharma, the maximum value of IC50 in extract of W. somnifera as per DPPH and NO scavenging assay was obtained as $352 \pm 22$ and $378 \pm 29 \mu \mathrm{g} / \mathrm{ml}$, respectively, when compared to ascorbic acid (taken as standard) [27].

The present study proved that field grown ethanolic leaf extract showed maximum antioxidant activity of $77.85 \%$ when compared to the literature of Shahriar et al. at concentration of $100 \mu \mathrm{g} / \mathrm{ml}$ in NO radical scavenging assay method [18]. Maximum concentration of total phenolic, flavonoids, and carotenoids contents in field grown ethanolic leaf extract of $W$. somnifera was obtained as $676.5 \mu \mathrm{g} / \mathrm{ml}$, $557.5 \mu \mathrm{g} / \mathrm{ml}$, and $469 \mu \mathrm{g} / \mathrm{ml}$, respectively, when compared to the literature of Chaudhuri et al. [28]. Nandi et al. (2011) reported that bioactive compounds separated from aqueous extract of $W$. somnifera are a potential source of antibacterial compounds with antioxidant 


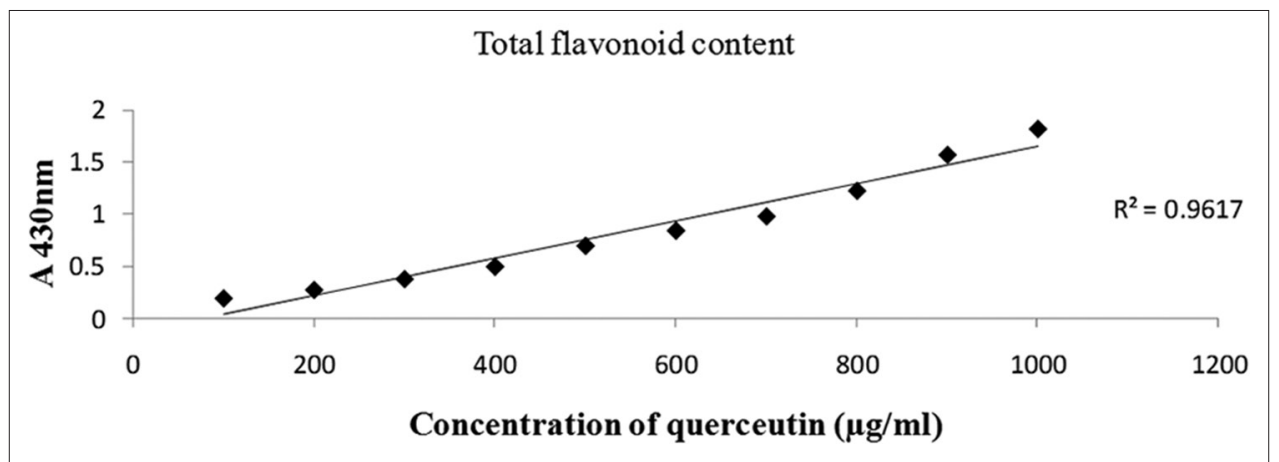

Fig. 4: Evaluation of total flavonoid contents in in vitro and field grown ethanolic leaf extract of W. somnifera from standard curve of quercetin

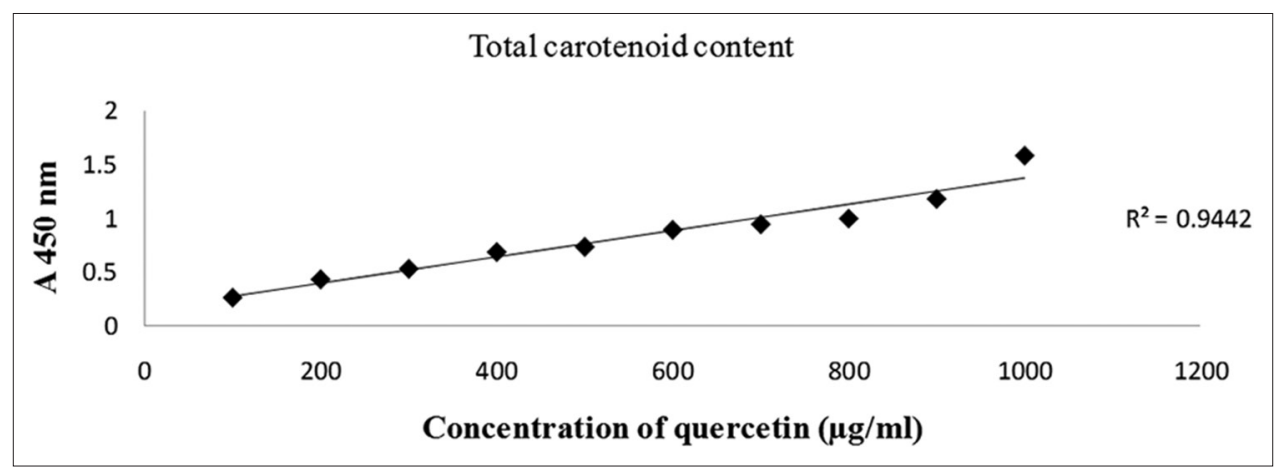

Fig. 5: Evaluation of total carotenoid contents in in vitro and field grown ethanolic leaf extract of W. somnifera from standard curve of quercetin

property [29]. Phenolic compounds are the most abundant secondary metabolites present in plant origin, which is the most important source for both human and animal diets. Phenolic content is more potent antioxidant than carotenoids because phenolics could act as hydrogen donors, quencher of singlet oxygen, and reducing agents [30,31], and thus it prevent the stress-induced oxidative stress [32].

IC50 indicates the potency of scavenging activity described by Shahriar et al. [18]. The IC50 values of in vitro and field grown ethanolic leaf extract of $W$. somnifera, gallic acid (standard) were obtained as $34.652 \mu \mathrm{g} / \mathrm{ml}, 29.510 \mu \mathrm{g} / \mathrm{ml}$, and $9.805 \mu \mathrm{g} / \mathrm{ml}$, respectively, in DPPH radical scavenging method. The IC50 values of in vitro and field grown ethanolic leaf extract of W. somnifera, curcumin (standard) were obtained as $85.024 \mu \mathrm{g} / \mathrm{ml}, 69.176 \mu \mathrm{g} / \mathrm{ml}$, and $58.917 \mu \mathrm{g} / \mathrm{ml}$, respectively, in NO radical scavenging method. According to the literature of Chaudhuri et al. [28], the results of IC50 values of in vitro root extract of $W$. somnifera and ascorbic acid (standard) were found as $650.37 \pm 107.18 \mu \mathrm{g} / \mathrm{ml}$ and $5.29 \pm 0.28 \mu \mathrm{g} / \mathrm{ml}$, respectively, in DPPH radical scavenging method. The IC50 values of in vitro plant extract and curcumin were obtained as $405.91 \pm 145.84 \mu \mathrm{g} / \mathrm{ml}$ and $90.82 \pm 4.75 \mu \mathrm{g} / \mathrm{ml}$, respectively, in NO radical scavenging method. Sharma and Sharma, (2014), have reported that multiple antioxidants are able to reduce inflammatory symptoms in inflammatory joint disease, acute and chronic pancreatitis, and adult respirator syndrome [27].

\section{CONCLUSIONS}

In the present study, we found that field grown ethanolic leaf extract of $W$. somnifera has excellent antioxidant activity to destroy the free radicals. This study also reveals the maximum concentration of total phenolic contents in field grown ethanolic leaf extract of $W$. somnifera as compared to in vitro extract. Antioxidant activity of plant extract is mainly due to the presence of phenolic compounds which are more potent antioxidant than other compounds because phenolics could act as a hydrogen donors, quencher of singlet oxygen, and reducing agents.
From this study, we conclude that $W$. somnifera has effective radical scavenging activity, implying their potential use in pharmacological and food industries. Further studies are required to isolate the active principles and antioxidant activity of individual extracts of different parts. The pharmacological validation in terms of modern medicine will be of great medicinal importance in future.

\section{ACKNOWLEDGMENTS}

The authors gratefully acknowledge the cooperation and assistance provided by technical staff of Department of Biotechnology, Lovely Professional University.

\section{REFERENCES}

1. Arnous A, Makris DP, Kefalas P. Effect of principal polyphenolic components in relation to antioxidant characteristics of aged red wines. J Agric Food Chem 2001;49(12):5736-42.

2. Gautam K, Kumar P. Extraction and pharmacological evaluation of some extracts of Vitex negundo Linn. Int J Pharm Pharm Sci 2012;4(2):132-7.

3. Lu F, Foo LY. Toxicological aspects of food antioxidants. In: Madhavi DL, Deshpande SS, Salunkhe SS, editors. Food Antioxidant. New York: Marcel Dekker; 1995.

4. Gulcin I, Oktay M, Kirecci E, Lu OK. Screening of antioxidant and antimicrobial activities of anise (Pimpella anisum L.) seed extracts. J Food Chem 2003;83(3):371-82.

5. Miller NJ, Rice CA. The relative contributions of ascorbic acid and phenolic antioxidants to the total antioxidants activity of orange and apple fruit juices and blackcurrant drink. J Food Chem 1997;60(3):331-7.

6. Cook NC, Samman S. Flavonoids-chemistry, metabolism, cardioprotective effects and dietary sources. J Nutr Biochem 1996;7(2):66-76.

7. Kathirvel A, Sujatha V. Phytochemical analysis and antioxidant activity of Barringtonia acutangula (L.) gaertn leaves. Int J Pharm Pharm Sci 2012;4(2):279.

8. Rice-Evans CA, Miller NJ, Bolwell PG, Bramley PM, Pridham JB. The relative antioxidant activities of plant-derived polyphenolic flavonoids. 
Free Radic Res 1995;22(4):375-83.

9. Kähkönen MP, Hopia AI, Vuorela HJ, Rauha JP, Pihlaja K, Kujala TS et al. Antioxidant activity of plant extracts containing phenolic compounds. J Agric Food Chem 1999;47(10):3954-62.

10. Loliger J. The use of antioxidants in food. In Free Radicals and Food Additives. London: Taylor and Francis; 1991. p. 121-50.

11. Kandampully A, Nikhil T, Bagwe T, Pala B. Withania somnifera (Ashwagandha): A source of therapeuctic agents. Int J Curr Res Chem Pharm Sci 2014;1(7):36-43.

12. Jesberger JA, Richardson JS. Oxygen free radicals and brain dysfunction. Int J Neurosci 1991;57(1-2):1-17.

13. Scarfiotti C, Fabris F, Cestaro B, GiulianiA. Free radicals, atherosclerosis, ageing, and related dysmetabolic pathologies: Pathological and clinical aspects. Eur J Cancer Prev 1997;6 Suppl 1:S31-6.

14. Khare CP. Indian Medicinal Plants-An Illustrated Dictionary. New Delhi: First Indian Reprint, Springer (India) Pvt., Ltd.; 2007. p. 717-8.

15. Anonymous. The Wealth of India Publications and Information Directorate. New Delhi: Council of Scientific and Industrial Research (CSIR); 1982. p. 580-5

16. Rani G, Grover IS. In vitro callus induction and regeneration studies in Withania somnifera. J Plant Cell Tiss Org Cult 1999;57(1):23-7.

17. Viji MO, Mathew MM, Parvatham R. Effects of light intensity and imbibition frequency of in vivo and in vitro propagated seeds of Withania somnifera (L.) poshita on germination. Int J Curr Microbiol Appl Sci 2013;2(11):354-60.

18. Shahriar M, Hossain MI, Sharmin FA, Akhter S, Haque A, Bhuiyan MA In vitro antioxidant and free radical scavenging activity of Withania somnifera root. Iosr J Pharm 2013;3(2):38-47.

19. Braca A, De Tommasi N, Di Bari L, Pizza C, Politi M, Morelli I Antioxidant principles from Bauhinia tarapotensis. J Nat Prod 2001;64(7):892-5

20. Mandal S, Hazra B, Sarkar R, Biswas S, Mandal N. Assessment of the antioxidant and reactive oxygen species scavenging activity of methanolic extract of Caesalpinia crista leaf. Evid Based Complement Alternat Med 2011;2011:173768.
21. Sreejayan, Rao MN. Nitric oxide scavenging by curcuminoids. J Pharm Pharmacol 1997;49(1):105-7.

22. Demiray S, Pintado ME, Castro PM. Evaluation of phenolic profiles and antioxidant activities of Turkish medicinal plants: Tilia argentea, Crataegi folium leaves and Polygonum bistorta Roots. J World Acad Sci Eng Technol 2009;54:312-7.

23. Jiao H, Wang SY. Correlation of antioxidant capacities to oxygen radical scavenging enzyme activities in blackberry. J Agric Food Chem 2000;48(11):5672-6.

24. Mahadevan A, Sridhar R. Methods in Physiological Plant Pathology. $3^{\text {rd }}$ ed. Chennai: Sivakami Publications; 1986. p. 9-11.

25. Taylor BS, Kim YM, Wang Q, Shapiro RA, Billiar TR, Geller DA Nitric oxide down-regulates hepatocyte-inducible nitric oxide synthase gene expression. Arch Surg 1997;132(11):1177-83.

26. Shah PB, Patel DS, Managoli NB. Evaluation of in-vitro anti-oxidan and free radical scavenging activities of Withania somnifera and Aloe vera. Asian J Pharm Technol 2012;2(4):143-7.

27. Sharma L, Sharma A. In vitro antioxidant, anti-inflammatory, and antimicrobial activity of hydro-alcoholic extract of roots of Withania somnifera. J Chem Pharm Res 2014;6(7):178-82

28. Chaudhuri D, Ghate NK, Sakar R, Mandal N. Phytochemical analysis and evaluation of antioxidant and free radical scavenging activity of Withania somnifera root. Asian J Pharm Clin Res 2012;5(4):193-9.

29. Nandi SP, Mehrotra S, Kirar V, Shyam R, Misra K, Srivastava AK Antioxidant and antimicrobial activities of aqueous extract of Withania somnifera against methicillin-resistant Staphylococcus aureus. J Microbiol Biotechnol Res 2011;1:40-5.

30. Dai J, Mumper RJ. Plant phenolics: Extraction, analysis and their antioxidant and anticancer properties. Mol 2010;15(10):7313-52.

31. Mehrizi MH, Shariatmadari H, Khoshgoftarmanesh AH, Dehghani F Copper effects on growth, lipid peroxidation, and total phenolic content of rosemary leaves under salinity stress. J Agric Sci Technol 2012;14:205-12.

32. Ruiz FA, Falcon MS, Lamela MC, Carballo EM, Gandara JS. Influence of major polyphenols on antioxidant activity in mencia and brancellao red wines. J Food Chem 2009;113:53-60. 